\title{
UN MANUSCRITO «APÓCRIFO» DE DON ÁLVARO O LA FUERZA DEL SINO
}

José Luis GonZÁLEZ Subías

Doctor en Filología Hispánica

Don Álvaro o la fuerza del sino es sin duda la obra teatral emblemática del romanticismo español. La prueba de ello es que, junto con el Don Juan Tenorio de Zorrilla, se trata del drama romántico más veces editado, y no existe colección de clásicos de la literatura española que no lo incluya entre sus textos. Hasta la publicación, en 1986, de la edición del Don Álvaro realizada por Ermanno Caldera (Madrid, Taurus), basada en los apuntes manuscritos existentes en la Biblioteca Histórica Municipal de Madrid, que reproducen el texto de la representación original de marzo de $1835^{\mathrm{t}}$, todas las ediciones de la obra realizadas hasta ese momento habían tomado como referencia la primera edición de 1835 (Madrid, Tomás Jordán) o la incluida en el tomo cuarto de las obras completas del duque de Rivas, publicadas veinte años después (Madrid, Biblioteca Nueva, 1854-1855), supuestamente corregida por el autor, o bien ambas.

El texto de la primera edición muestra claramente cómo el duque de Rivas limó su drama para darlo a la imprenta; y, desde entonces, las numerosas reediciones de la obra a lo largo de todo el siglo XIX (Yenes, 1839; Repullés, 1845 y 1852; Biblioteca Nueva, 1854-55; Cipriano López, 1857; Ducazcal, 1879; Fortanet, 1881; Barcelona, Montaner y Simón, 1884-85; Moreno y Rojas, 1889) repitieron básicamente sin alteraciones -salvo modificaciones ortográficas- el texto de la edición príncipe.

\footnotetext{
' Signatura: Tea/ 1-25-2.
} 
Hasta ahora nada hacía pensar que las abundantes representaciones del Don Álvaro llevadas a cabo desde su estreno hubieran alterado sustancialmente el texto editado por Saavedra en 1835. El otro único manuscrito que se conocía de la obra hasta el momento, conservado igualmente en la Biblioteca Municipal de Madrid y que estuvo destinado a una representación efectuada en la capital en $1851^{2}$, no ofrece variaciones con respecto a las ediciones impresas, salvo los peculiares rasgos ortográficos del momento en que fue copiado. Sin embargo, estamos en condiciones de afirmar que, en alguna ocasión, en el mismo siglo XIX, el texto de Rivas fue manipulado deliberadamente para su puesta en escena. Así lo confirma el descubrimiento de un nuevo manuscrito que debemos añadir a los anteriores y que, frente a éstos, posee la peculiaridad de ofrecer un Don Álvaro, si no alterado en su contenido esencial, sí lo bastante retocado como para poder afirmar que nos hayamos ante una versión adaptada, con unas variantes frente al original muy significativas, las cuales manifiestan una clara intencionalidad de estilo por parte del dramaturgo - pues sin duda lo era- que realizó tal copia y arreglo.

Este manuscrito, de menores dimensiones que los apuntes conservados en la Biblioteca Histórica Municipal ${ }^{3}$, consta de 192 páginas y se haya incluido en un volumen en octavo, encuadernado sin duda en el siglo XIX, inserto entre dos obras que guardan estrecha relación, por distintos motivos, con el drama del duque de Rivas: una edición de La vida es sueño de Calderón, impresa en Madrid (Librería Cuesta), en 1872, que aparece en primer lugar; y el Don Juan Tenorio editado igualmente en Madrid, por la imprenta de Cipriano López, en 18574.

Presentado como «Don Álvaro ó la fuerza del sino, drama original en cinco jornadas, en prosa y verso, por D. Angel Saavedra, Duque de Rivas $»^{5}$, la página inicial del manuscrito, donde figuran el título de la obra y su autor, incluye bajo el nombre de éste la fecha de «1835», así como la dedicatoria a Alcalá Galiano -no la extensa de la primera edición, sino la abreviada que figura en las restantes ediciones-, entrecomillada (lo que nos indica claramente que el autor de esta copia está citando a Saavedra), en la que encontramos ya una variante con respecto a la dedicatoria incluida en las ediciones del texto. Donde en éstas se lee: «en prueba de constante y leal amistad en próspera y adversa fortuna», en el manuscrito apa-

${ }^{2}$ Signatura: Tea/ 1-179-1.

${ }^{3}$ Frente a los 210x155 milímetros que señalaba Caldera para éstos, las hojas del nuevo manuscrito miden 195x 120 milímetros aproximadamente.

${ }^{4} \mathrm{El}$ volumen en que se incluye el mamuscrito se encuentra entre las obras de teatro decimonónico incluidas en mi biblioteca particular. Fue adquirido en Madrid.

${ }^{5}$ Reproduzco sin alteraciones la ortografía de todas las citas textuales que realizo en este trabajo, lo cual permitirá no sólo comprobar los rasgos ortográficos del manuscrito, sino compararlos con los utilizados en la edición de 1855, que usaré para citar la versión original del duque. 
rece: «en prueba de constante y leal amistad, en la próspera como en la adversa fortuna».

Las peculiaridades de este curioso manuscrito saltan pronto a la vista. Son muchas las pistas que nos hacen pensar que se trata de una copia destinada a una posible representación de la obra. Así parece confirmarlo el hecho singular de que, tras la relación de «personas» que intervienen en la acción (pp. 2-3), se incluyan dos páginas en las cuales se resume esquemáticamente los lugares en que suceden las diferentes jornadas y escenas (algo insólito tanto en los manuscritos teatrales como en las ediciones); o la indicación «cae el telon», que aparece al finalizar la jornada tercera, inexistente en las ediciones del texto. Además, las acotaciones escénicas de esta versión difieren notablemente de las incluidas tanto en los manuscritos originales del estreno como en las ediciones posteriores de la obra, al ser muchísimo más breves que éstas e, incluso, siendo eliminadas en numerosas ocasiones.

Es indudable que el texto no fue escrito por su verdadero autor ni se trata de una copia destinada a ser impresa. Sin embargo, resulta llamativo y chocante el hecho de que no aparezcan en el manuscrito las anotaciones, tachaduras o correcciones características de los apuntes teatrales destinados a un montaje escénico. El texto se presenta impoluto, sin enmiendas, salvo escasas ocasiones en que, por un error, el copista-adaptador borra lo escrito para volver a escribir de nuevo encima. Tampoco aparece junto a los personajes el nombre de los actores que habrían intervenido en el supuesto montaje para el que podría haber sido destinado el manuscrito, como ocurre en los conservados en la Biblioteca Municipal y solía ser lo habitual en estos casos. ¿Se debe quizá a que la obra no se representó en ninguno de los grandes teatros de la época, sino en alguna casa particular? ${ }^{6}$ ¿Por qué se tomó la molestia el «copista» de reproducir a mano un texto del que existían tantas ediciones? ¿Quién fue capaz de alterar el texto del Don Álvaro y para qué lo hizo?

Quizá la última de estas preguntas sea la de respuesta más inmediata: para ser representado, adaptado a la época y al público a quien iba dirigido. Pero nos atreveremos a aventurar otras respuestas. Hubo de volver a escribir el texto porque las variantes que introdujo en él son tan significativas que habría resultado imposible escribirlas sobre un ejemplar ya impreso de la obra. Quien hizo tales «arreglos» fue sin duda escritor, con un importante dominio del diálogo escénico; posiblemente un dramaturgo de su tiempo. Por último, no siempre los manuscri-

'Algo bastante improbable, si tenemos en cuenta la complicada escenografía de la obra y el elevado número de personajes que intervienen en ella. En los teatros particulares existentes en las casas de ciertas clases aristocráticas o pudientes solían representarse piezas dramáticas más sencillas, preferentemente comedias. 
tos teatrales existentes incluyen el nombre de los actores junto al de los personajes; máxime si aún no han sido representados ${ }^{7}$. Todas las preguntas anteriores confluyen en una; definitiva para comprender y valorar en su justa medida la importancia del texto que estamos analizando: ¿cuándo se escribió esta versión del Don Álvaro?

La inclusión del manuscrito entre una edición impresa en 1857 y otra en 1872 , junto con las propias características de la encuadernación en que se incluye, el tipo de papel y las peculiaridades gráficas del texto, podrian hacernos pensar rápidamente que éste fue escrito en torno a las fechas en que fueron impresas las piezas que lo acompañan; pongamos, aproximadamente, entre 1850 y 1880 . El análisis de la obra, desde el punto de vista estilístico y de sus rasgos ortográficos, así como su comparación con las características que presentan en estos aspectos las diferentes ediciones del drama, es determinante para concretar aún más el momento aproximado de su confección. Así, he podido concluir que el autor de esta copia adaptada tomó como referencia una edición de la obra no anterior a la de la incluida en las obras completas de 1854-1855; posiblemente ésta o la de $1857^{8}$.

Aunque los rasgos ortográficos que presenta el manuscrito, coincidentes en un amplio porcentaje con los de la edición de 1855 (corrección de leísmos; preferencia por escribir «mujer», en vez de «muger»...), también avalarían esta tesis, me limitaré tan sólo a señalar algunas variantes textuales que se producen en esta última edición, con respecto a la anterior de 1845, y que son recogidas igualmente por el manuscrito. Así, donde en las ediciones de la obra anteriores a 1855 el padre Melitón afirmaba: «Yo lo hago con gusto» (escena $2^{\mathrm{i}}$, jornada V); en la edición de las obras completas, al igual que en el manuscrito, se lee: «Yo lo hago con mucho gusto». $\mathrm{O}$ donde, hasta la edición de 1845 , pone el poeta en boca de $\mathrm{D}$. Alfonso (escena $6^{\mathrm{a}}$, jornada $\mathrm{V}$ ) el siguiente verso: « $i$ No encontrais en mi semblante...»; en 1855 y en la versión manuscrita aparece: « $i$ No veis en mis ademanes...». Baste como muestra que, hasta 1845 , la escena sexta de la última jornada no incluía acotación alguna al finalizar la misma; mientras que la edición de 1855, al igual que el manuscrito, incluye la siguiente indicación: «(salen ambos precipitados)».

Partamos, por tanto, de que el texto fue escrito al menos después de 1855. ¿Qué razones existen para descartar que se trate de una versión realizada en la década de los ochenta, o incluso después? Al margen de las características del

TAsí ocurre con los manuscritos que se conservan destinados a la censural y que, normalmente, incluyen el dictamen del censor al final del drama. No es el caso tampoco del manuscrito que estamos comentando.

"No creo que tomara la edición de 1879 , porque eso supondría datar esta versión con posterioridad a esta fecha; algo que, como trataré de demostrar, me parece bastante improbable. 
volumen en que se halla encuadernado, comentadas con anterioridad, existe una razón de peso, basada exclusivamente en los rasgos ortográficos del manuscrito. Aunque, al tratarse de una copia no destinada a ser leída en una edición impresa, es posible que su autor no prestara tanta atención a la ortografía", el texto está plagado de errores e imprecisiones que en los años ochenta habían sido casi totalmente superados; como es el caso de la confusión $g / j$; la tendencia a separar palabras compuestas del tipo «buena ventura», «bien aventurado» o «medio día»; así como vacilaciones acentuales extremas en palabras llanas y agudas, que en la década de los ochenta no era ya frecuente encontrar ${ }^{10}$.

En general, las características ortográficas del manuscrito, cotejadas con las mostradas por los textos escritos entre 1840 y la década de los ochenta, nos invitan a situar la composición de esta copia-adaptación hacia los años sesenta; un momento de transición en que muchos de los errores ortográficos visibles en los textos de la época comienzan a desaparecer en las ediciones impresas. No obstante, éstos todavía persisten; máxime si -como es el caso que nos ocupa- se trata de manuscritos no destinados en principio a su lectura. Son estos errores, precisamente, los que nos impiden pensar en una versión escrita en los años setenta -aunque no es descartable, teniendo en cuenta los desatinos ortográficos que aún se encuentran esporádicamente en esta década-; a favor de lo cual estaría, sin embargo, la sorprendente modernidad que el autor del manuscrito manifiesta al escribir casi siempre correctamente la grafía $x$ ante consonante, rasgo común en los textos escritos en la década de los setenta, pero apreciable también en la década anterior, y la modernidad mostrada asimismo en las numerosas variantes sintácticas y de estilo desplegadas a lo largo de todo el texto. Resulta difícil precisar más la fecha de composición del manuscrito a partir de sus rasgos ortográfícos, teniendo en cuenta las vacilaciones ya señaladas -presentes a lo largo de buena parte del siglo XIX-y que éstas variaban dependiendo de los autores, las imprentas e incluso el lugar de edición de los textos.

Cabe pensar que, si el duque de Rivas falleció en el verano de 1865, la copia hubo de realizarse con posterioridad a su muerte, pues no parece razonable que un dramaturgo se permitiera alterar, en vida del autor y de manera tan significativa, un texto tan conocido como éste. Pero son sólo conjeturas. Lo cierto es que, con bastante probabilidad, este nuevo manuscrito del Don Álvaro debió de escribirse en una fecha indeterminada entre las décadas sesenta y setenta; una época en la que por otra parte se convirtió en práctica habitual, en los textos dramáticos,

"Así lo demuestran el aparente descuido y la rapidez con que parece estar escrito el texto, a pesar de la pulcritud mostrada por el copista-adaptador al no incluir ninguna tachadura.

"No obstante, estas características varían bastante en función de los autores y de los textos. Es muy habitual, por ejemplo, encontrar errores en ediciones impresas fuera de Madrid, que en la capital estaban ya prácticamente desterrados. 
la reproducción gráfica del lenguaje popular y de sus peculiaridades fónicas en diferentes zonas de España, como rasgo no sólo de tipismo sino como recurso destinado a producir efectos humorísticos.

La utilización de este recurso no es una práctica exclusiva de los años en que, a partir del teatro de funciones por horas, nacido en los años inmediatamente anteriores al estallido de la "Gloriosa», se impone en la escena española el lenguaje del género chico. A finales de la década de los cincuenta son muy abundantes las obras en que los autores reproducen los rasgos fónicos y las incorrecciones propias del habla popular, con preferencia de origen andaluz". El andalucismo se puso de moda en el lenguaje de las piezas teatrales decimonónicas de los años sesenta y setenta, especialmente en obras breves de un solo acto, editadas con frecuencia en tierras andaluzas ${ }^{12}$. Pero este tipo de obras y su influjo llegaron también a la capital, en un momento en que los teatros y las imprentas de Madrid difundían un aluvión de comedias y otras variedades dramáticas en las que se utilizaba como efecto escénico la reproducción del habla popular inculta ${ }^{i 3}$.

Precisamente es ésta una de las características más destacadas del manuscrito que estamos comentando. En la célebre escena de ambiente costumbrista incluida por el duque de Rivas al comienzo del drama, el copista-adaptador de su texto modifica las intervenciones de Preciosilla y otros personajes populares como el habitante $2^{\circ}$, el majo o el tío Paco, e inserta en su discurso algunos rasgos fónicos andaluces e incorrecciones lingüísticas propias del habla popular. Así, tanto la gitana como el mencionado habitante se dirigen al oficial y al canónigo como «su mersé» (escenas $1^{\mathrm{a}}$ y $2^{\mathrm{a}}$ ); el tío Paco altera vulgarmente el adverbio «muy»: «una cosa mu grande» (escena $2^{a}$ ); o, más significativamente, observemos la transformación que ha sufrido, en manos del adaptador, la siguiente intervención del majo (escena $2^{a}$ ):

"También son frecuentes las ocasiones en que los dramaturgos hacen hablar a sus personajes más populares e incultos con marcado acento asturiano (La muerte de César, de Ramón Crook y Saturnino Esteban Collantes, 1866; El correo de la noche, de Enrique Zumel, 1873), o incluso en un francés (Este cuarto se alquila, arreglo de Dacarrete y Cisneros, 1858) y un inglés (Very Well, arreglo de Antonio Hurtado, 1870) igualmente macarrónicos.

${ }^{12}$ Los ejemplos que pueden aducirse son muy numerosos: Antaño y ogaño, de Pedro Aniceto Sobrado (Madrid, 1858); El tio Cachumeno, de José Arcos y Pérez (Cádiz, 1859); Un duelo de jitanos, de Francisco Gómez Sánchez (Málaga, 1863, 2a ed.); El churi del ecijano, de José Ma Honor (Sevilla, 1866, $2^{\text {i }}$ ed.); Cuantas veo, tantas quiero, de José Navarrete (Cádiz, 1867); El tio Zaratán, de José $\mathrm{M}^{\mathrm{a}}$ Gutiérrez de Alba (Salamanca, 1871, $3^{\mathrm{a}}$ ed.); Los dulces de la boda, de Eusebio Blasco (Madrid, 1871); Mientras viene mi marido, de Javier de Burgos (Cádiz, 1872)...

${ }^{13}$ Así ocurre, por ejemplo, en Dos mirlos blancos, de Manuel Ortiz de Pinedo (1860), El querer y el rascar, de Narciso Serra (1861, $2^{\text {a }}$ ed.), Un nudo... morrocotudol, de Luis Cuenca (1879), o Soledad, de Eusebio Blasco (1879). 
MAJO. Es verdad que es todo un hombre, muy duro con el ganado, y muy echado adelante. ${ }^{14}$

Majo.

Verdá que es todo un hombre, muy duro con el ganado, y muy echao pa alante.

En la primera escena de la jornada segunda, localizada en la posada de Hornachuelos, volvemos a encontrarnos con una ambientación costumbrista, y el autor del manuscrito modifica de nuevo el lenguaje de los personajes populares que intervienen en ella, transformando las fórmulas de tratamiento utilizadas por el tío Trabuco, el mesonero y su mujer, en «usté» y «mercé». $\mathrm{O}$ el arriero, que se expresa con un lenguaje más apropiado a su humilde condición al cometer la vulgar incorrección de usar el infinitivo con valor imperativo: «Está diciendo comerme!».

Otra importante variación que podemos destacar, entre las muchas que abundan en el manuscrito, se halla al final de esta misma escena, donde el copista-adaptador altera el orden de las intervenciones de los personajes. Obsérvese, además, los retoques textuales, que afectan sin duda al estilo y a la fluidez del original:

ALCALDE. Buenas noches, y que haya juicio y silencio.

ESTUDIANTE. Pues me voy á mi cuarto. (Se va á meter en el del viajero incógnito.)

MESONERO. Hola, no es ese, el de mas allá.

ESTUDIANTE. Me equivoqué.

Estudiante. En efecto, vóime á mi cuarto (va á meterse en el del viajero misterioso).

Mesonero. ¡Hola! ese no, el de mas allá.

Estudiante. Me equivocaba.

Alcalde. Buenas noches y que haya juicio y silencio.

Son las partes de la obra escritas en prosa las que sufren un mayor número de alteraciones; algo, por otra parte, lógico, pues haber modificado sustancialmente el verso del drama habría supuesto escribir, en realidad, un nuevo texto. Estas alteraciones, imposibles de reproducir en el reducido espacio de un artículo,

14 Citaré siempre el texto de la versión original a partir de la edición de las obras completas (1854-1855). Debajo del texto original, y separada por una línea de puntos, pondré la versión del manuscrito. Para distinguir la intervención de los personajes en el original de la versión manuscrita, obsérvese que además, en la primera, el nombre de éstos está escrito en mayúscula, como ocurre en la edición de 1855; y, siguiendo el manuscrito, los personajes que intervienen se indican en minúscula. 
son notables en la segunda escena de las jornadas primera, cuarta y quinta, así como en la escena primera de la jornada segunda, coincidentes todas ellas con momentos en los que intervienen en el diálogo o bien personajes populares -la mayoría-, o bien militares (escena $2^{a}$, jornada IV) o clérigos (diálogo entre el hermano Melitón y el padre Guardián; escena $2^{a}$, jornada V).

Modificaciones significativas se producen también en la escena sexta de la jornada tercera -cuyo número, en el manuscrito, se olvida poner-, donde, aparte de las continuas variaciones que el autor de la versión sigue introduciendo en el texto, éste pone en boca del teniente una oración que en la obra original corresponde al capitán que dialoga con él:

CAPITAN. Pero por este lado no va tan bien. Teniente, vaya usted á reforzar con la mitad de la compañia las gucrrillas que estan en esa cañada; que yo voy á acercarme á la compañía de Cantabria; vamos, vamos.

SOLDADOS. Viva España, viva España, viva Nápoles. (Marchan)

Teniente. $\quad$ Pero por este lado no va tambien [sic] la cosa...

Capitan. Teniente, vaya V. á reforzar con la mitad de la compañía las guerrillas á esa cañada; yo voy á acercarme á la compañia de Cantabria. ¡Granaderos! en marcha!

Soldados

(con alegría). Viva Nápoles! Viva España!!! (desaparecen)

Este tipo de variaciones, consistentes en cambiar el personaje que interviene en un momento determinado del drama, se repite en la escena segunda de la jornada cuarta, en la que un grupo de oficiales comentan entre sí el duro castigo decretado por el rey Carlos de Nápoles para quienes se batan en duelo. Obsérvese cómo, amén de otras variantes, el comentario puesto por Rivas en boca del oficial $1^{\circ}$ es adjudicado por el autor del manuscrito al oficial $3^{\circ}$ :

OFICIAL $1^{\circ}$. Lo cierto es que la ley es dura; pena de muerte por batirse, pena de muerte por ser padrino, pena de muerte por llevar cartas; qué sé yo. Pues el primero que caiga...

OFICIAL 2". No, no es tan rigurosa.

OFICIAL $1^{\circ}$. ¿Cómo no? Vean ustedes. Leamos otra vez. (Se acercan á leer el edicto y se adelantan en la escena los otros.)

Oficial $1^{\circ}$. Repito que la ley es en extremo dura: pena de muerte por batirse, idem por ser padrino, idem por llevar cartas, idem... qqué sé yo?... Pues al primero que caiga...

Oficial $2^{\circ}$. No, no es tan rigorosa. 
id. $3^{\circ}$.

¿No? no es nada; leámosla otra vez mas (Estos se alejan á examinar el edicto y los otros se adelantan á la escena).

O, en la misma escena, poco después, un texto atribuido a Pedraza en la versión original pasa a ser dicho por el teniente en el manuscrito:

PEDRAZA. Bien puede; pues segun me ha dicho un sargento de mi compañia, andaluz, el tal don Felix está aquí con nombre supuesto, y es un marqués riquísimo de Sevilla.

Teniente. ¡Bien puede! segun yo he oido á un sargento de mi compañía, andaluz, Don Félix está aquí con nombre supuesto y es un marqués riquísimo de Sevilla.

$Y$, finalmente, de nuevo en la misma escena, el comentario expresado al unísono por los oficiales $1^{\circ}$ y $4^{\circ}$ en la obra de Rivas es adjudicado a los oficiales $3^{\circ}$ y $4^{\circ}$ en el manuscrito, y en intervenciones separadas:

OFICIALES

$I^{\circ} \mathrm{Y} 4$.

Oficial $3^{\circ}$.

id. $4^{\circ}$.
Era un charlatan, un fanfarron.

Era un fanfarron!

Era un charlatan!

Incluso, en la escena siguiente de la misma jornada, el personaje que en todas las ediciones del drama figura como un capitán, que custodia a don Álvaro y dialoga con él, en la nueva versión manuscrita aparece como «Oficial». Además, la escena cuarta del original es incluida por el copista-adaptador en la escena anterior, sin separación alguna, con lo que, a partir de ese momento, todas las escenas de la jornada cuarta se reducen en un número en el manuscrito; la escena quinta será la cuarta, y así sucesivamente.

Son tan numerosas las variaciones textuales existentes entre el Don Álvaro del duque de Rivas y el del manuscrito, que sería necesario transcribir por completo su contenido para poder dar cuenta exacta de su alcance. Pero, aun siendo las partes en prosa las más modificadas por el incógnito adaptador, las variantes afectan también al verso de la obra. En ocasiones son muy someras, simples alteraciones de una forma verbal; como cuando Leonor, dirigiéndose a su criada Curra, exclama: «AAy Curra! si penetraras» (escena 6a, jornada I); donde el autor del manuscrito sustituye la forma del pretérito imperfecto de subjuntivo «penetrases» por la anterior. En este caso, la modificación resulta del todo incorrecta, pues se rompe la rima del romance mantenida por Rivas a lo largo de toda la escena; pero en otras ocasiones las variaciones incluidas no sólo no perturban el discurrir 
del verso, sino que incluso modernizan -y a veces mejoran- el estilo y el sentido del discurso:

DON ALVARO. no soy culpado, no, dulce señora;

D. Álvaro. no soy culpable, no, dulce Señora: [escena 7a , jornada I]

Así ocurre con estas reiteradas variantes en la escena octava de la jornada primera:

MESONERO. Entra, que entrar es razon,

Mesonero. Sea, que entrar es razon,

MESONERO. ¿Cómo? ¿cómo? Ya lo sé...

Mesonero. ¿Cómo? qué dices?... Ya sé...

MESONERO. Quiera Dios no haya cargado

Mesonero. Quiera Dios no haya arramblado

MESONERA. que se encuentra en grande apuro.

Mesonera. que se encuentra en grave apuro.

Una de las más interesantes modificaciones que sufre el texto se encuentra al comienzo de la jornada segunda, en la posada de Hornachuelos. Mientras, en el texto original, el duque de Rivas da principio a la escena primera con la intervención de un estudiante que canta al son de una guitarra, al tiempo que bailan a su compás tres parejas, en el manuscrito son sólo dos las parejas que danzan, y en los versos de la canción -dos seguidillas- se incluye una importante variante. Recordemos el estribillo del texto:

Viva Hornachuelos, vivan de sus muchachas los ojos negros.

Estos versos, que se repetirán en la versión original tras la segunda y última estrofa, en el manuscrito son incluidos igualmente en el bordón de la primera seguidilla, pero se modifican en la siguiente: 
Viva Hornachuelos, vivan de sus mugeres los pies pequeños.

A veces, las deliberadas manipulaciones del autor del manuscrito sobre lo que está «copiando» varían claramente el sentido inicial dado a su texto por el duque de Rivas. Así ocurre en el siguiente fragmento tomado del diálogo entre Leonor y el padre Guardián del convento de los Ángeles (escena $7^{\mathrm{a}}$, jornada II), donde, como observaremos, el adjetivo «benignos» que complementa al sustantivo «intentos» en un duro hipérbaton es transformado por el copista en un predicativo, «benigno», referido al fraile:

DOÑA LEONOR. A vos, cual solo remedio de todos mis infortunios; si benignos los intentos que á estos montes me conducen permitís tengan efecto.

Leonor.

Á vos, cual solo remedio de todos mis infortunios, si, benigno, los intentos que á estos montes me conducen permitís tengan efecto.

Arreglo que considero acertado, al igual que la modificación añadida en otro verso de la misma escena, puesto de nuevo en boca de Leonor:

DOÑA LEONOR. es inmutable... lo fio, es inmutable.

Leonor. es inmutable... lo fio, irrevocable.

Otros cambios que afectan especialmente al léxico de la obra -y estamos ciñéndonos ahora sólo a las partes en verso- se encuentran esparcidos a lo largo de toda la versión manuscrita. Nos conformaremos, ante la imposibilidad de transcribir todos los existentes, con señalar algunos ejemplos más:

DON CARLOS. Ánimo, noble amigo, cobrad ánimo y aliento:

D. Cárlos. Ánimo, noble amigo...

Cobrad confianza y aliento: [escena $7^{\mathrm{a}}$, jornada III] 
CIRUJANO. ya le he sacado la bala,

El cirujano. $\quad$ ya le he extraido la bala [escena 9: jornada III]

DON ALVARO. Demandad perdon al cielo.

D. Álvaro. ¿Clemencia pedid al cielo! [escena $!^{a}$, jornada IV]

DON ALVARO. de horror ó de burla objeto.

D. Alvaro. de horror ó desprecio objeto! [escena $3^{a}$, jornada IV]

DON ALFONSO, y que las espadas hablen.

D. Alfonso. $\quad$ y que los aceros hablen. [escena $9^{\prime \prime}$, jornada $\mathrm{V}$ ]

DON ALFONSO. Tú entre los indios creciste,

D. Alfonso. Tú entre los indios naciste, [escena $9^{: 1}$, jornada V]

Ausencia y reducción de acotaciones, añadido de otras, modernización y adaptación del estilo a una época distante en algunas décadas al momento en que el duque de Rivas entregó por primera vez al Teatro del Príncipe su redacción del Don Alvaro, y arreglos que no desdoran en absoluto el original sino que, en su conjunto, dotan al texto de una mayor fluidez y, en ocasiones, fuerza dramática. Sin duda el autor de esta apócrifa versión manuscrita, presentada como el Don Álvaro del duque de Rivas, y que posiblemente fue representada en algún escenario madrileño entre las décadas de 1860 y 1870 , fue escrita por una mano conocedora de su oficio, nacida de un dramaturgo que, con respeto -pero sin reverencia- al original, se atrevió a introducir unas modificaciones que difícilmente Rivas hubiera aceptado de haber conocido su existencia ${ }^{15}$.

Podría parecer difícil superar la maestría de una obra considerada ya, en los años inmediatos a la muerte de su autor, como un símbolo de los tiempos gloriosos del triunfo del Romanticismo en la escena española; pero alguien se

\footnotetext{
15 Confieso que me hubiera gustado demostrar que fue el propio duque de Rivas quien escribió esta desconocida versión del texto antes de su muerte. Hubiera sido un hallazgo de primera magnitud que habría revolucionado todos los estudios existentes sobre el Don Alvaro o la fuerza del sino. Por las fechas en que parece estar compuesto el manuscrito, no es descartable, pero lo considero una posibilidad muy remota que no soy capaz de apoyar.
} 
atrevió a reescribir el texto y alterarlo, con un resultado que nos parece, cuando menos, sorprendente. La arrebatadora fuerza pasional de la última escena del drama no pierde intensidad con las alteraciones introducidas por este anónimo copista-adaptador; incluso, en nuestra opinión, la supera. Dejemos que sean los textos quienes hablen por nosotros una vez más... y juzguemos:

DON ALVARO. (Desde un risco, con sonrisa diabólica, todo convulso, dice:) Busca, imbécil, al P. Rafel... Yo soy un enviado del infierno, soy el demonio esterminador... Huid, miserables.

TODOS. ¡Jesus, Jesus!

DON ALVARO. Infierno, abre tu boca y trágame. Húndase el cielo, perezca la raza humana; esterminio, destruccion... (Sube á lo mas alto del monte y se precipita.)

D. Álvaro

(desde un elevado risco, á donde se ha alejado, dice, con sonrisa diabólica, y todo convulso): Busca, imbécil, al padre Rafael!... Yo soy un enviado del infierno, el demonio exterminador!... ¡Huid, miserables!

Todos. ¡Jesus! ¡Jesus!

D. Álvaro.

Infierno, abre tus fauces y trágame. Húndase el firmamento y perezca la raza humana!... exterminio!... ¡destruccion! (desde el mas alto risco se precipita á los abismos.) 
ALEUA/18

JOSÉ LUIS GONZÁLEZ SUBÍAS

Don Alvaro

0

La fuerza del dino,

Drama oviginal en cince jounadas, en prosa y verso.

por

9. Angel Sacuedra, Dugue de Pivar 1835 .

Dedicado al Exmo Iv. I. Intonico Alcalá Galiano, por el autor, "en prueba de constante y leal amistad. en ta próspera como en La adversa fortuna."

$1^{\text {a }}$ página del manuscrito

240 

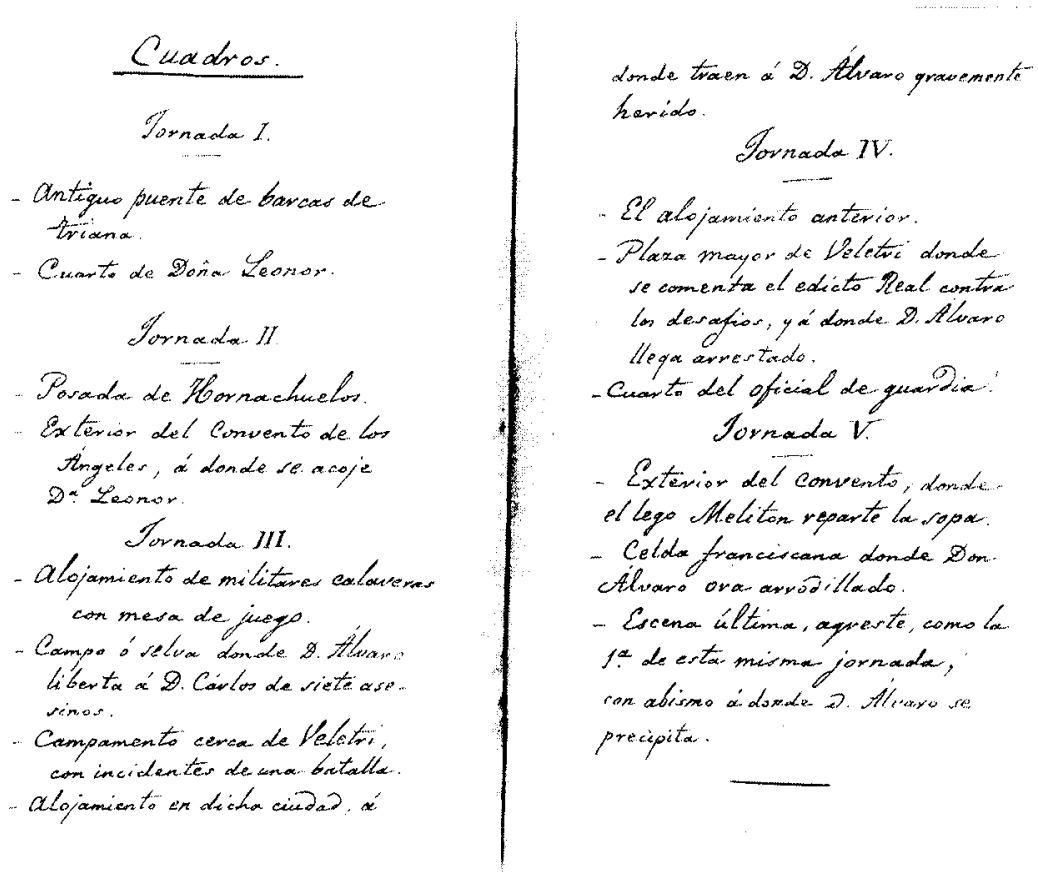

Resumen de los diferentes espacios que aparecen en el drama (pp. 4-5 del Ms.) 


\section{Hornadow $T$.}

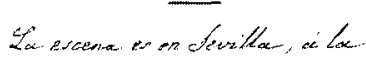
saida de la tardo y vilue entrado. del antigur puente de trarcas de

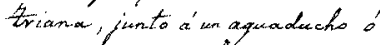
puerts de a agua de tomaras, rodrazo Le bancos

$$
\text { - iscena } \operatorname{ta}^{\alpha}
$$

Oficial . Bromes. Preciorithe yourta

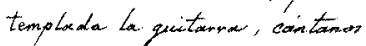
una rondanto pronto, promto

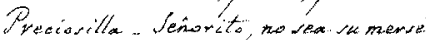
tain sipito - Díme antes esa mano y Le Live' La buena venturas. Oficinal- Luita, quita, no quiero tero za-

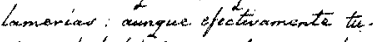
viernes habilidad ale decirme to que me he de suceder. no greicero ointo.... casiviempre convieme igmonarto.

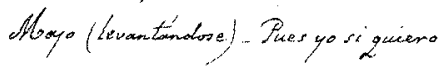

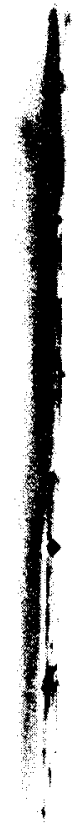

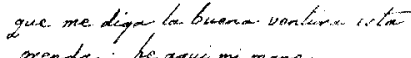

$$
\begin{aligned}
& \text { prempla: he agui mi mowo }
\end{aligned}
$$

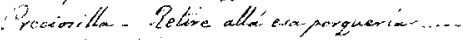

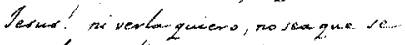

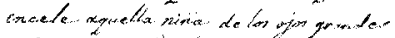

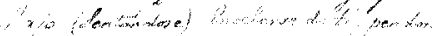
$\therefore$ orith $\quad b, \alpha, x$

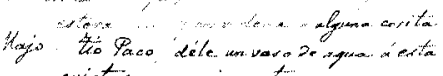

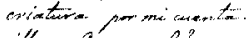

Sresisulth. icon pumal?

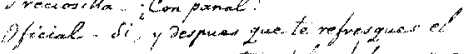

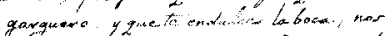

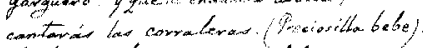

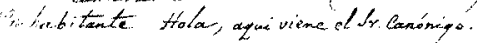
orcentrar...

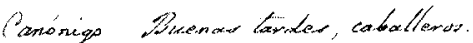
Wisbitionte 2" temiamor no temen to abicha. Le ver a' ne merse'estat tarder, of

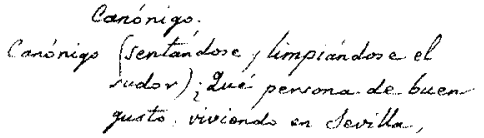

Comienzo de la jornada primera 